OPEN ACCESS

Edited by:

Claire Napawan,

University of California, Davis,

United States

Reviewed by:

Lance W. Vail,

Independent Researcher, Sequim,

WA, United States

Wael Salah Fahmi,

Helwan University, Egypt

*Correspondence:

Brook Muller

bmuller7@uncc.edu

Specialty section

This article was submitted to Water and Built Environment,

a section of the journal

Frontiers in Water

Received: 07 August 2021 Accepted: 30 November 2021

Published: 14 January 2022

Citation:

Muller B (2022) Ablutionary Urbanisms: Water Infrastructures, Cultural Production and Charitable

Dispensation. Front. Water 3:755066.

doi: 10.3389/frwa.2021.755066

\section{Ablutionary Urbanisms: Water Infrastructures, Cultural Production and Charitable Dispensation}

\author{
Brook Muller* \\ College of Arts + Architecture, University of North Carolina at Charlotte, Charlotte, NC, United States
}

With interest in advancing inclusive urban landscapes and guided by principles of social and cultural sustainability, this essay speculates as to localized water infrastructures as "ablutionary urbanisms," important forms of contemporary design expression in a context of rapid growth, widening inequalities, climate change and lack of resilience. It derives inspiration from vernacular precedents in advocating for an integrated, decentralized approach to addressing current urban water challenges. It explores the contemporary relevance of the sabil, a prominent civic feature of Islamic cities intended for the charitable dispensation of water. More specifically, this essay considers the contemporary relevance and potency of the sabil-kuttab, a hybrid building type unique to the city of Cairo in which a school (kuttab) sits atop a sabil. Such a type offers helpful guidance in devising principles and precepts relevant to contemporary infrastructural design in that: (1) it offers encouragement to advocate for distributed urban water systems as civically prominent elements of cities, particularly as these systems combine with other important community-focused programmatic features; and (2) given a reimagining of urban water systems as critical forms of cultural production, it offers encouragement for interdisciplinary teams to commit to the task of infrastructure planning as a promising locus of integrative design.

Keywords: water, design, infrastructure, culture, urban, vernacular, charity

\section{CONTEMPORARY URBAN WATER INFRASTRUCTURES AND THE RELEVANCE OF THE VERNACULAR}

This essay is guided by the conviction that urban water infrastructures are at once critically important forms of contemporary design expression, district-scale sustainable development, and cultural production in a context of rapid urbanization. It considers cities in desert environments subject to climate change impacts, with a focus on the "sublime mess" that is the sprawling City of Cairo, and looks to vernacular examples as inspiration in devising integrated, localized approaches to addressing water and associated urban challenges ${ }^{1}$. In particular, it considers the sabil, a prominent civic feature of the Islamic urban landscape intended for the charitable dispensation of water, one in which a ground level space allowing access to the public sits atop cisterns below. More specifically, this essay considers the contemporary relevance and potency of the sabil-kuttab,

\footnotetext{
${ }^{1}$ May al-Ibrashy of Cairo-based Athar Lina describes the Cairo as such (personal correspondence, January 18, 2021) given its moments and aspects of great beauty and sublimity within a context of poverty, pollution and uncontrolled growth.
} 
a hybrid building type unique to the city of Cairo in which a school (kuttab) sits atop a sabil. Literature on the sabil, other vernacular water systems, Islamic history and beliefs, ecological design, climate change, and relevant contemporary political, planning and urban circumstances informs this theoretical exercise of transposing a vernacular model to a contemporary context as a form of speculative design research.

The marrying of cultural and water infrastructures embodied in the sabil-kuttab inspires notions of "ablutionary urbanisms," or "celebratory infrastructures" as described and theorized by Mira Engler; ablutionary urbanisms are those that speak to an elevated civic presence for localized (decentralized or distributed) water systems that offer resilient functionality at the same time they signal continuity between heritage and urban water histories and more inclusive infrastructural futures ${ }^{2}$. The example of sabil-kuttabs prompts exploration, inspired by urban water historian Smith's (2013) notion of the "infrastructure of ideas," of creative approaches and collaborative strategies for working on integrated water systems as neighborhood and district amenities in a context of dramatic urban growth, ever widening economic disparities, in-migration, environmental deterioration and injustice and questionable priorities as they relate to infrastructural investments and given the lingering legacies of modernist, centralized approaches. While the beneficiaries of contemporary ablutionary micro-urban projects would be the same as those of sabil-kuttabs, that is to say city dwellers of all walks and stations, the benefactors are fundamentally different, not the affluent elite and instead nimble assemblages of public servants, designers, artists, engineers, urban ecologists, policy experts, community members, urban activists, anthropologists, and others. Such a construct contests the hegemony of state imposed infrastructural projects and policies as one of the case studies to be described so powerfully attests?

\section{WATER AS CARRIER OF DESIGN VALUE}

The call to this special issue of Frontiers of Water asks the question: "How can design fields contribute to improved performance and sustainability of urban water systems?" To that end, although many actors are involved, the role of designers will be highlighted in what follows. This investigation of hydro-cultural infrastructures and the contemporary relevance of the vernacular appeals urgently to those in design and creative fields to revisit their commitments and reposition their work. Seeking an "alternative understanding of what we can do," as May al-Ibrashy, founder of the Cairo-based NGO Megawra Built Environment Collective encourages, and assuming myriad forms of practice designers might adopt, how might reckoning with rapid growth, environmental degradation, economic marginalization and their attendant consequences expand our view of the beneficiaries of the synthesizing expertise of creatives ${ }^{3}$ ? What channels of inquiry in the realms of

\footnotetext{
${ }^{2}$ The "celebrated approach" is but one that Engler explores in rethinking the design of waste disposal and treatment systems and facilities. See Engler (1995).

${ }^{3}$ Personal correspondence with the author, January 18, 2021; see also: https:// megawra.com. website accessed November 6, 2021.
}

architectural, urban and infrastructural design gain momentum by Pope Francis' exhortation that those with the means and professional capacity see themselves as instruments for the liberation of the poor?

Public Interest Design provides a powerful, mission and service driven model for the role of the architect in contemporary society committed to the betterment of communities and to helping those less fortunate ${ }^{4}$ And yet we now add water and concede the glaring reality that the architectural profession has relegated the medium to a tertiary role, perceiving it as the domain of engineers and other technical experts and not a crucial life-giving substance as well as a design protagonist that has enormous creative potential to positively disrupt boundaries, physical, disciplinary and otherwise. The conceptualization of a design problem is a conceptualization of the world-of histories and futures, natures and cultures-an indicator of commitment to principled action founded on a higher calling, however explicit or thoroughly articulated these motivations happen to be. Often unwittingly, given the projects they take on and an ambivalence toward water they harbor, designers all too frequently proceed from a narrow conception of their roles and support approaches to development neither sustainable nor inclusive $^{5}$. A more critical and intentional stance that reckons with impacts of climate change and rapid urbanization embraces a global awareness while attending to the particulars of local hydrological and other conditions, recognizes water as carrier of value, and leads to a different kind of purposefulness, with access and adequate sanitation, denied to so many, an obligatory standard in the urban landscape.

\section{THE SABIL-KUTTAB}

Sabils are public water dispensaries found throughout the Islamic urban landscape, from Morocco to the Balkans to Turkey to cities in the Middle East ${ }^{6}$. Translated loosely as "road or path," sabils assume prominent locations in the preindustrial city, typically at a confluence of important streets and alleys ${ }^{7}$. A cistern built out of solid rock or fired brick and waterproof mortar sits below grade to store and keep water cool and is filled regularly after being cleaned and purified. A ground level room overlooking the street features an iron grill through which water is handed out to passers-by, at the same time allowing sufficient ventilation to air-cool the water. Adorned with mosaics and inscriptions, sabils celebrate the generosity and spiritual wealth of their benefactors, and as such are celebrated cultural landmarks in the Islamic city.

As described by El Didi and Corbera, the sabil "belongs to a historical, voluntary and charity-driven institution of the Islamic ethical system known as waqf, which underpins the irreversible public endowment of one's assets or property, dedicated for

\footnotetext{
${ }^{4}$ See: https://www.publicinterestdesign.com (“Design Like You Give a Damn”). ${ }^{5}$ See Mitchell (2002) for a compelling treatment of the outfall of techno-managerial modernist projects in Egypt.

${ }^{6}$ It deserves mention that modest-sized, privately supplied sabils remain prevalent to this day in urban and rural Egypt, providing safe drinking water and in some instances irrigation water. See El Didi and Corbera (2017).

${ }^{7}$ Lamei Mostafa (1989, p. 34).
} 
charitable purposes ${ }^{8}$." Given the level of investment required (of money, time and labor), a sabil represented a form of benefaction undertaken by important and affluent civic leaders, often constructed in association with other water infrastructure improvements. Lamei Mostafa describes the civic and spiritual import of the sabil given the symbolic significance of water and the link between this precious substance and commitments and dedication of the highest order and for the greater good:

Providing a public space that provides water for men and animals implements one of God's commandments and follows the dictates of the hadith regarding charity on behalf of God. Why these structures became such sophisticated and elaborate buildings, particularly under the Mamluks and Ottomans, however, is another question, since the modest basin or fountain would have fulfilled the required charitable function. Probably they sought to build, not just a source of water, but a holy building suitable for divine revelation, since water was seen as a divine and not a mundane gift $^{9}$.

In Cairo, elevating further notions of generosity and ethical duty, it is not uncommon for a kuttab, a space for orphaned children to memorize the Qur'an and to develop handwriting skills, to occupy the top level of the sabil. Sometimes a kuttab was built at the same time as the sabil; in other instances, during the Ottoman period for example, schools were added to sabils sometime after the latter were built. Whether part of the original program or introduced afterward, the interweaving of places of learning and places to access water lends sabil-kuttabs deep symbolic meaning. If "the Muslim architect tried to attain perfection by introducing the sabil as a metaphor for a spring in Paradise," the sabil-kuttab, in providing a setting for intellectual discovery, spiritual growth and accommodation of critical physiological needs, brings an even higher sense of unity, purposefulness and symbolic exaltedness ${ }^{10}$.

Notable examples of sabil-kuttabs in Cairo include the SabilKuttab of Sultan Mahmud (construction began in 1163), the Sabil-Kuttab Sultan Qaytbay, located at the beginning of al-Saliba Street in the Citadel Square (Mamluk era, 1479), and the Sabilkuttab of Abd al-Rahman Katkhuda from the mid eighteenthcentury (Ottoman period) ${ }^{11}$. These three examples, centuries apart in time of construction as they are, provide indication of the longstanding significance of this hybrid building/infrastructure type and are to be understood as part of a larger, ever evolving Cairene water supply system implemented in premodern times in response to recurring challenges of "overcrowding and the scarcity of drinking water ${ }^{12}$ " as the city "grew into a great urban conglomerate." While "running water in the house was a privilege preserved for the upper classes," members of Cairo's lower and

\footnotetext{
${ }^{8}$ El Didi and Corbera (2017, p. 129).

${ }^{9}$ Lamei Mostafa (1989, p. 35).

${ }^{10}$ Lamei Mostafa (1989, p. 37).

${ }^{11}$ Note: During his reign Sultan al-Ashraf Abu al-Nasr Qaytbay (1468-96), a Burji Mamluk Sultan of Egypt, stabilized the state and its contested northern boundaries, expanded in trade, and became a major patron of the arts and design. For information on the sabil-kuttab of Sultan Qaytbay see: http://islamicart. museumwnf.org/database_item.php?id=monument;ISL;eg;Mon01;14;en\&cp.

${ }^{12}$ Levanoni (2008, p. 205, 203).
}

lower middle classes living in "common people's residential complexes" had to access to water supplies only by venturing beyond their households ${ }^{12}$. The landmark-like infrastructures that emerged to meet the needs of people of all classes made their imprint upon the social life and the physical fabric and patterning of the city.

\section{CAIRO: PRECARIOUS WATER FUTURES IN THE SUBLIME MESS}

Cairo once had its functioning system of sabil-kuttabs to meet the water needs of many of its inhabitants, most of which have now fallen into disuse, although many are preserved. It now benefits from a modern piped network, part of an extensive legacy of centralized water infrastructure building in Egypt overall ${ }^{13}$. That said, the city faces significant water quality problems as industrial wastewater, sewage discharge, agricultural runoff and other pollutants flow into the Nile. It also confronts a rising groundwater problem as a function of this centralized infrastructure, what geographer Jessica Barnes describes as "abundance side-by-side with scarcity ${ }^{14}$." With shallow bedrock characterizing its geology, there is throughout Cairo an excess of trapped and rising groundwater from leaky pipes as is the case in numerous other Egyptian cities (it deserves mention that the presence of groundwater presented a major challenge during the restoration of the Sabil Muhammad 'Ali Pasha in al-Aqqadin Cairo: "the foundations were settling unevenly, threatening the building with collapse") ${ }^{15}$.

Growth in Cairo's ex-urban fringes is rampant. Some of this is planned, with the construction of a New Administrative Capitol (NAC) in the desert 30 miles east of Cairo and begun in 2015 the most celebrated example ${ }^{16}$. Yet even before NCA, middle class and upper middle-class Cairenes were moving to gated suburban developments in the periphery, leaving behind the incredible congestion and pollution and relegating those remaining there to make do. Meanwhile, other peripheral urbanisms grow in a very different, less planned way, with informal settlements continually sprouting on Cairo's edges and former villages transforming into 'dormitory' towns, with the disappearance of farmland one consequence. With so many poor moving to these new settlements, the average income level "of peri-urban Cairo is significantly below the urban average ${ }^{17}$." Services in these informal areas are often overburdened and, according to David Sims, "can reach a crisis point. In many mature informal areas, water, power and sewerage networks were extended rather

\footnotetext{
${ }^{13}$ It is the case that Egypt increased piped water supply between 1998 and 2006 from 89 to $100 \%$ in urban areas and from 39 to $93 \%$ in rural areas, this despite rapid population growth (in many locations however this water is not potable). On the other hand, only about one half of Egypt's population is connected to sanitary sewers; this lack of wastewater infrastructure results in 50,000 childhood deaths per year of diarrhea.

${ }^{14}$ Barnes (2014, p. 35).

${ }^{15}$ Dobrowolska and Fahmy (2004, p. 22).

${ }^{16} \mathrm{NAC}$, funded in part by the Egyptian military, is a shining symbol of (entrenched) power and affluence combined with disregard of climate change and the urban poor.

${ }^{17}$ Sims (2010, p. 43).
} 
haphazardly in the 1970s and 1980s, and they now must function for several times the original design populations ${ }^{18}$." Assessing the state of infrastructure in these parts of the metropolis, Sims argues that "in all informal areas public amenities could be vastly improved ${ }^{19}$."

The circumstances of the example of Cairo, considering the co-present reality of the attendant problems and shortcomings of legacy water infrastructures in existing urban neighborhoods, rapid growth of unplanned and underserviced settlements in the outskirts, and the construction of unsustainable, wasteful and typically gated glorification projects (see NAC) that leave the urban to tend for themselves inspires the refashioning of the sabil-kuttab as a recommitment to peoples of all social and economic stations. This particular form of "infrastructure reimagined" offers, as part of a multi-faceted "portfolio" approach, one promising means of addressing the multiple water, hygiene and other needs of urban dwellers in a proactive manner, where concerns of access, resilience and ecological responsiveness, are given due. Two contemporary examples of localized water infrastructures serve as examples of water infrastructure as civic placemaking, one in Cairo and the other in eThekwini Metropolitan Municipality (City of Durban, South Africa). Each in their own is reminiscent of sabils and sabilkuttabs and informs a programmatic design agenda at the same time they prompt reflections on the positioning of designers working on localized urban water systems in the city today.

\section{A SABIL-KUTTAB FOR THE TWENTY-FIRST CENTURY}

\section{Al-Khalifa Heritage and Environmental Park}

A function of aging legacy centralized infrastructures, the alKhalifa neighborhood of Cairo, like many others, finds itself with excess groundwater in an arid environment. As mentioned, this is not a natural phenomenon; in this case, the presence of groundwater results from leakage from water supply and sewerage networks of nearby, uphill tenement complexes. Large volumes of this water, trapped above bedrock not far below grade, threaten the integrity of the al-Ashraf Khalil and Fatima Khatun domes, two significant heritage sites built in the thirteenth century and in dire need of restoration. Rising damp laden with salt disintegrates the lower courses of stone masonry and threatens the collapse of the domes' walls due to differential settlement.

While the seemingly obvious solution would be to fix these networks, such costly interventions require political will and investment, both lacking. An alternative approach involves converting what is causing damage to the heritage conservation sites into the very resource that can drive urban redevelopment. With this goal in mind, an interdisciplinary, international team organized through the Cairo-based Megawra Built Environment Collective under the supervision of the Egyptian Ministry of Antiquities and the Cairo Governorate devised a strategy

\footnotetext{
${ }^{18}$ Sims (2010, p. 106).

${ }^{19}$ Sims (2010, p. 107).
}

to combine the recycling of water, celebration of heritage, environmental quality enhancement, and attending to the needs of al-Khalifa neighborhood residents as the basis for functional water systems design and urban place making. Linking the future of the domes with community development goals, the team proposed intercepting the groundwater, lifting it using solar pumps to a vacant strip of land across the street from them (an elevated site that varies in its height above the street from 3 to $6 \mathrm{~m}$ ) and utilizing this newly available resource as the basis for the creation of the al-Khalifa Environment and Heritage Park. The recycled water is to be used to irrigate plantings so as to create a lush green space in the middle of the dusty, polluted city, a space intended primarily for women and children-two constituencies who have precious little access to such urban amenities-as well as tourists.

In 2017 Megawra organized an "International Groundwater School” attracting architects, landscape architects, engineers, heritage conservationists, product designers and others from around the world and called upon them to develop fitting, integrated and aesthetic solutions to this problem. Participant teams were tasked to develop design proposals for the park in a manner that acknowledged and protected the domes across the street and that took advantage of the presence of water as a free asset and design instigator. Key features of the park included active and passive treatment systems for the contaminated water intended to have strong aesthetic and spatial presence and play important environmental education roles. Trickling filters, an initial step in the filtration and cleansing system, would serve as a gateway to the park and a threshold between the al-Khalifa and Zenhoum neighborhoods. Following initial treatment, the water would make its way through the park in subsurface wetlands for further cleansing and then would daylight, in a treated state, as a children's water play feature. This water would then be directed to a cistern that would store water to be used for irrigation of plantings and other purposes. Standing in a circular plaza atop the cistern, one would be able to appreciate the view of the domes across the street. The park's cultivation of relationships between water, history, culture and education recall qualities of the sabil-kuttab, and yet the system would be deployed laterally vs. vertically (cultural and water infrastructures set side-by-side instead of one over the other).

The al-Khalifa Environment and Heritage Park represents at once a decentralized, place-adapted, and neighborhood scale infrastructural system and a much-needed community asset made possible by utilizing a neglected source, treating it and redirecting it. As such this model of a sabil-kuttab for the twenty-first century is a replenishing operation, with charitable dispensation involving the creation of much-needed, high quality outdoor spaces serving multiple generations (it should also be noted that excess water would be routed to water-using neighboring businesses such as marble cutters, an important, novel form of dispensation for a neighborhood in need of economic stimulus). Reenlisting and treating the residues of a modernist infrastructural legacy become the very means of protecting notable heritage assets and helping to ensure their long-term care. Water is the systems activator linking a microurban site to a larger culture, community and fabric; the 
liability now serves a new and different infrastructural and cultural reality.

\section{City of EThekwini's (Durban's) Ablution Blocks}

As with so many cities around the world, the eThekwini Metropolitan Municipality operates in a constant state of everexpanding need for water and sanitary services given the growing number of underserved in-migrants living in unplanned settlements. In order to meet this challenge comprehensively, the Municipality's Housing, Architecture, Health, and Water and Sanitation Departments initiated in 2004 the community ablution blocks (CABs) program ${ }^{20}$. CABs are repurposed, mobile shipping containers situated throughout urban and peri-urban eThekwini to provide communal water and sanitation facilities to the approximately one million people living in informal settlements. Given that piped systems would be too expensive and would never reach a large percentage of the population, CABs offer an equitable alternative and demonstrate commitment on the part of the municipality to basic rights of access, a moral economy of water as antidote to uneven and unfair infrastructural investments that is the legacy of apartheid.

Doug Saunders describes the phenomenon of "arrival cities," fringe urbanisms where people from the hinterlands move in search of employment and a higher quality of life ${ }^{21}$. Rather than characterizing these as slums, Saunders views these as places of tremendous vibrancy, energy and possibility and worthy of public expenditure. "It is here," Saunders argues, "rather than at the 'macro' state or 'micro' household level, that serious and sustainable investments from governments and agencies are most likely to create lasting benefits ${ }^{22}$." A CAB as a contemporary form of dispensation for those transitioning to the city in seek of opportunity serves as the very kind of investment discipline Saunders would endorse, an endowment directed toward more just urban futures.

\section{al-Khalifa Park Meets EThekwini's Ablution Blocks (A Speculative Hybrid)}

For cities like Cairo, might it be possible to build from a contemporary interpretation of sabil-kuttabs represented by the al-Khalifa Park and combine this with the concept of community ablutionary blocks and, when promising or necessary, the coopting of the detritus of legacy modernist infrastructures (when seen as a resource) in order to create systems prototypes configured to respond simultaneously to multiple needs? Ablutionary urbanisms as hybrid localized infrastructures could provide water and hygiene and other important functions depending on the particularities of the inherited hydrological and infrastructural context and assessment of neighborhood needs; they could simultaneously offer programming in the form of community centers, schools, libraries, health clinics, plazas

\footnotetext{
${ }^{20}$ See: https://www.connective-cities.net/en/good-practice-details/gutepraktik/ ethekwini-communal-ablution-blocks-for-informal-settlements; website accessed November 6, 2021.

${ }^{21}$ See Saunders (2010).

${ }^{22}$ Saunders (2010, p. 3).
}

and squares, places of performance, recreation, and conviviality, respite and shade. When elevated in standing, water-centric urban interventions can also serve as living repositories of history and heritage and forums for interface and interpretation in an everchanging context and unprecedented levels of uprootedness. Such a realizable vision entails commitment to a process of design and planning in which water infrastructures are conceived from the outset as spatial and cultural assets, as stable and recognizable civic markers, amidst the urban flux.

\section{GUIDING PRINCIPLES FOR THE SABIL-KUTTAB FOR THE TWENTY-FIRST CENTURY}

Guiding principles of a hybrid approach to decentralized water infrastructures, inspired by vernacular precedents and the SabilKuttab in particular, and realized through a process of systems design as a form of urban placemaking, are described as follows.

\section{Water as Systems Generator at the District Scale}

District and neighborhood scale micro-urban ablutionary projects can assume an importance in terms of function and presence in the civic imaginary all out of proportion to their size. This follows from a holistic approach and an expansive manner of defining the problem, and the relating of water issues and to a broader set of contextual conditions: environmental, cultural, economic, demographic, other ${ }^{23}$. Water assumes a rightfully privileged role in this process, serving as the activating medium that flows across disciplinary and spatial domains to make new systems go. Water becomes a protagonist and formative element in the creative consciousness, an activator vs. a technical piece addressed only after major decisions have been arrived at.

\section{Urban Water Systems as a Design Challenge}

Water as connective medium in the creative process of developing systems accommodating of multiple community goals follows from new disciplinary arrangements, those that are "integrated and collaborative across sectors and boundaries to achieve urban water sustainability ${ }^{24}$." As part of this and after a decades' long hiatus, designers (re)turn their attentions to infrastructure and lend their skills artfully to pressing water and related challenges of the day. The design process begins with a basic configuration of the water system, that is to say, the development of a water schematic that depicts basic components, interactions and flows, and next looks to spatial, experiential and aesthetic opportunities that such a schematic elicits; this represents an inversion of the normative design process that begins with space and then adds water. Such an operational sequence holds the potential to usher in new aesthetic paradigms,

\footnotetext{
${ }^{23}$ For an excellent example of instantiating urban design projects by delving into the particularities of systems and mapping neighborhood resource flows, see the framework developed by the Civic Ecology Institute: http://civicecologyinstitute. org/contact-us/.

${ }^{24}$ The quote is from the Frontiers of Water special issue call.
} 
forms of design expression that "amplify natural and cultural processes" and that align the meeting of basic material needs for all members of urban communities with other dimensions of human fulfillment ${ }^{25}$.

In the densifying, space constrained urban landscape with increasing functional demands placed upon it, the need for creative approaches to water infrastructure is critical. The idea of "cosmetically mitigating infrastructure" by hiding it underground, back-of house or on the roof no longer obtains ${ }^{26}$. The amenity IS the infrastructural system and positive placemaker as opposed to the kind of support system that "occupies so much space that it overwhelms the amenity it was intended to provide 27 ." The designer's three dimensional thinking skills are at a premium; the need to stack more value and function in confined real estate speaks to landscape architect Randy Hester's challenge to designers go straight to the heart of conflict and recognize it as an incredible expressive and aesthetic opportunity. ${ }^{28}$ Engler would describe this design approach as an act of choreography in which "no screening or buffer zones exist ${ }^{29}$." With back of stage morphing to center, as Strang encourages, infrastructure systems "can be designed with a formal clarity that expresses their importance to society, at the same time creating new layers of urban landmarks, spaces and connections ${ }^{30}$."

\section{Urban Water Systems as Forms of Cultural Production}

Understanding water infrastructural systems as relevant subjects of design inquiry is to bestow upon them significance beyond that of invisible life support for "true" forms of cultural production, notable buildings for example; indeed, they become critical forms of cultural production in their own right. Granting these systems such status, we are encouraged to ask what values they represent and symbolize, not only in terms of their physical presence but also what they reveal as far as notions of legacy, inheritance, and progress. As the story goes, centralized modernist infrastructures as forms of cultural production intentionally and unapologetically admit of a rupture with the past. At the same time, many would say, because they come to fruition through a conviction of a better future, a taking for granted and a discounting of the present ensues, with detritus, externalities and marginalization a consequence. As political scientist James Scott argues in speaking of the modernist mindset: "the certainty of a better future justifies the many short-term sacrifices required to get there ${ }^{31}$." And yet in a strange sense, it could be said that the opposite is true, that centralized modernist infrastructures as forms of cultural production represent the prioritization of shorter term investments, leaving next generations to deal with the future "side-effects" they produce, as the sociologist Beck (1992) would describe it. Much can be found

\footnotetext{
${ }^{25}$ Engler (1995, p. 11)

${ }^{26}$ Strang (1996, p. 11).

${ }^{27}$ Strang (1996, p. 13).

${ }^{28}$ See Hester (2006).

${ }^{29}$ Engler (1995, p. 20).

${ }^{30}$ Strang (1996, p. 10).

${ }^{31} \operatorname{Scott}(1998$, p. 95$)$.
}

in the material record to support both perspectives, and perhaps the simultaneous modernist discounting-the-present-to-build-abetter-future/building-the-present-as-discounting-future-effects has something to do with the very rupture with the past just touched upon.

The kinds of distributed water infrastructures discussed in this essay-forms of cultural production brought about by integrative design processes-derive value by looking to the past, to history and the hydrological vernacular. Of concern are not only the specific technologies and systems employed that might inform contemporary approaches, but also the attitudes latent in these, and the notions of benefaction and care they embody; in other words, the cultural meaning of these acts and works. Interest in the vernacular is not the wistfulness of nostalgia and instead an active process of looking to the values that inhere in urban water heritages as fundamental to the art of creating contemporary systems that might renew the notion of waqf as a public endowment and continuous charity.

This approach to urban water systems finds resonance with the position of the Standing Rock Nation as it confronts the running of the Dakota Access Pipeline through its ancestral lands and the prospect of contamination of their sacred waters, a project that continues a multi-generational legacy of harm to both land and people. As Nick Estes describes the attitude of the Sioux: "There is no separation between past and present, meaning that an alternate future is also determined by our understanding of the past. Our history is the future ${ }^{32}$." In a similar manner of meaning making, an interdisciplinary entity such as Megawra, in creating projects and leading processes that help inhabitants of a poor neighborhood understand and take pride in their past while offering them a better quality of life through improvements that marry water infrastructure and urban design, also gives them agency in imagining fuller, thriving collective futures. Further, as the example of al-Khalifa Park attests, the very rupture and detritus of modernism, "a mélange of excess resulting from a throw-away culture," provides one contemporary field and often the ready-to-hand material for realizing forms of cultural production that restitch temporal links and perform that which is honorable and poetically charitable ${ }^{33}$.

\section{WATER INFRASTRUCTURE DESIGN IN A DRAWDOWN RENAISSANCE}

If the Modern Technical Age is to remain human, it cannot overlook the trust that our ancestors have left with us. - Marshall G.S. Hodgson ${ }^{34}$.

Fourteenth century historian Ibn Khaldun speaks to the process repeated in society after society, empire after empire, where decline in creative and cultural production signals that of urban civilization overall (Khaldun, 1967). Where might we place cultural production in our contemporary global civilization on this ascending and descending curve (or stated differently,

\footnotetext{
${ }^{32}$ Estes (2019, p. 14-15).

${ }^{33}$ Engler (1995, p. 11).

${ }^{34}$ Hodgson (1974, p. 98)
} 
what direction does the curve now move to intersect with the realities of the present)? Given our material affluence, perhaps we are at the apogee, a high point in cultural wealth a consequence of a flourishing worldwide civilization and global economy. Others believe our civilization falls short, that, given humaninfluenced climate change, a fraying ecological fabric upon which we all depend, and failure to attend to needs and identities of so many millions and in the most basic of ways, we are in the midst of a global "drawdown," to reorient the meaning of Hawken's provocative term ${ }^{35}$. The inability to grant so many a life of meaning leaves ourselves amidst a heartbreaking cultural impoverishment with every sign of continued decline. While a consequence of the larger political indifference, severe economic stratification, and lack of collective will, there is also the matter of the narrow obligations of the designer and a fragmented approach to water, indicators-and abettors-of this decline.

With the traditional sabil-kuttab as an important symbol of Islamic culture, a notable bequeaths a life-giving substance to the community. With an affluent minority producing or commissioning the goods of civilization such as sabils, "the quality of this culture tended to depend directly on the material prosperity of its well-to-do patrons ${ }^{36}$." Today the circumstances differ markedly in terms of neoliberalism gone awry on the one hand and tremendous creative capacity for urban problem solving at the localized level on the other. Surgical, microurban interventions, forms of social justice eminently manifest in the way we deploy systems in space, have the potential to radiate

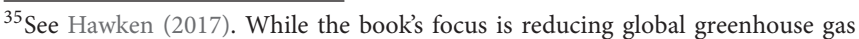
emissions, efforts to do are part of a larger social and cultural process of drawdown that seeks to simultaneously reduce environmental degradation and lift people out of poverty.

${ }^{36}$ Hodgson (1974, p. 105).
}

outward in terms of the impact such projects can have on the lives of many. While the subject of a next paper, what is required is the development of cross-disciplinary, project and community focused educational platforms that align design, heritage, ethics, infrastructure planning, and other realms of inquiry, precisely what Megawra has achieved and to great effect.

Within the sublime mess of the urban present designers can play an important role in borrowing from cultural infrastructures of the past in developing assemblages that work with water in innovative ways and that revisit the idea that "charity in water is perceived as an (spiritual) honor ${ }^{37}$." A sabil-kuttab for our times serves as an example of an infrastructural type in which cultural meaning, collective moral will, water systems and urban design find synthesis. It speaks to the critical potential of urban water system projects as inventive, necessary and hopeful forms of design expression. That they might become so is possible through formation of assemblages involving creative disciplines working toward a shared goal of making more just, functional, and beautiful a little piece of the urban collective that is the city. Recognizing some of the shortcomings of the legacy of the modernist infrastructural projects, ablutionary urbanisms catalyze a transition to more equitable urban futures: water futures, other futures, ones born out of a design imaginary with roots in the past and a firm grounding in the realities of the hydrological present.

\section{AUTHOR CONTRIBUTIONS}

The author confirms being the sole contributor of this work and has approved it for publication.

\footnotetext{
${ }^{37}$ El Didi and Corbera (2017, p. 138).
}

\section{REFERENCES}

Barnes, J. (2014). Cultivating the Nile: The Everyday Politics of Water in Egypt. Durham, NC and London: Duke University Press.

Beck, U. (1992). Risk Society: Towards a New Modernity. Translated by Mark Ritter. London: Sage Publications, Ltd. (original German edition 1986).

Dobrowolska, A., and Fahmy, K. (2004). Muhammad 'Ali and His Sabil. Cairo: The American University in Cairo Press.

El Didi, H., and Corbera, E. (2017). A moral economy of water: charity wells in Egypt's Nile Delta. Dev Change 48, 121-145. doi: 10.1111/dech.1 2286

Engler, M. (1995). Waste landscapes: permissible metaphors in landscape architecture. Landscape J. 14, $11-25$.

Estes, N. (2019). Our History is the Future: Standing Rock Versus the Dakota Access Pipeline, and the Long Tradition of Indigenous Resistance. London, New York: Verso.

Hawken, P. (ed) (2017). Drawdown: The Most Comprehensive Plan Ever Proposed to Reverse Global Warming. New York: Penguin Books.

Hester, R. (2006). Design for Ecological Democracy. Cambridge, MA: The MIT Press.

Hodgson, M. (1974). The Venture of Islam: Conscience and History in a World Civilization. Volume One The Classical Age of Islam. Chicago and London: The University of Chicago Press.

Khaldun, I. (1967). The Muqaddimah: An Introduction to History (The Classic Islamic History of the World). Translated by Franz Rosenthal; Abridged and Edited by N.J. Darwood. Princeton and Oxford: Princeton University Press (Bollingen Series).

Lamei Mostafa, S. (1989). "The Cairene Sabil: Form and Meaning," in Muqarnas VI: An Annual on Islamic Art and Architecture, ed O. Grabar (Leiden: E.J. Brill).

Levanoni, A. (2008). Water supply in medieval middle eastern cities: the case of Cairo. Al-Masaq 20, 179-205. doi: 10.1080/0950311080228 3408

Mitchell, T. (2002). Rule of Experts: Egypt, Techno-Politics, Modernity. Berkeley, CA: University of California Press.

Saunders, D. (2010). Arrival City: The Final Migration and Our Next World. Toronto: Alfred A.

Knopf.

Scott, J. (1998). Seeing Like a State: How Certain Schemes to Improve the Human Condition Have Failed. New Haven, CY: Yale University Press.

Sims, D. (2010). Understanding Cairo: The Logic of a City Out of Control. Cairo: The American University of Cairo Press.

Smith, C. (2013). City Water, City Life: Water and the Infrastructure of Ideas in Urbanizing Philadelphia, Boston and Chicago. Chicago: The University of Chicago Press. 
Strang, G. (1996). Infrastructure as landscape. Places 10, 9-15.

Conflict of Interest: The author declares that the research was conducted in the absence of any commercial or financial relationships that could be construed as a potential conflict of interest.

Publisher's Note: All claims expressed in this article are solely those of the authors and do not necessarily represent those of their affiliated organizations, or those of the publisher, the editors and the reviewers.
Any product that may be evaluated in this article, or claim that may be made by its manufacturer, is not guaranteed or endorsed by the publisher.

Copyright (C) 2022 Muller. This is an open-access article distributed under the terms of the Creative Commons Attribution License (CC BY). The use, distribution or reproduction in other forums is permitted, provided the original author $(s)$ and the copyright owner(s) are credited and that the original publication in this journal is cited, in accordance with accepted academic practice. No use, distribution or reproduction is permitted which does not comply with these terms. 